UDC 581.91

LBC 28.5

\title{
FLORA OF THE CEMETERIAL TERRITORIES OF VOLGOGRAD AND THE VILLAGE OF ARZGIR OF STAVROPOL TERRITORY
}

\author{
Victoria S. Samokish \\ Volgograd State University, Volgograd, Russian Federation \\ Vadim A. Sagalaev \\ Volgograd State University, Volgograd, Russian Federation
}

\begin{abstract}
For the first time, the article provides information about the features of the plant community of the cemeterial territories of Volgograd and the village of Arzgir of Stavropol Territory. The inventory of plants was carried out by the route method. Each route was about $10 \mathrm{~km}$. For the first time, such cemetery territories were studied: the cemetery of the village of Gornaya Polyana and the Kirov cemetery in Volgograd, cemeteries No. 1 and No. 2. in the village of Arzgir of Stavropol Territory. The identification of samples was carried out by standard methods in the Laboratory of Experimental Biology of Volgograd State University (VolSU). The collected species are stored in the Botanical Herbarium of the University. The article presents an annotated list of cemeteria plants, including 44 species, indicating data on habitats and the date of collection. This annotated list will be the basis for conducting monitoring studies in the field of environmental protection, as well as optimizing the regional network of protected areas. A comparative analysis of the flora of the studied territories was carried out, according to which a slight difference was revealed. This difference is explained by the fact that the cemeterial territories of Volgograd is located inside the largest urbanized city, unlike the small village of Arzgir, and the species composition of plants in these two territories depends on the person because most of the species are cultivated. The data obtained as a result of the study will be used to develop questions of systematics, geography and ecology of plants. The revealed diversity of plants in the studied regions expands our knowledge about the ecology and distribution of species, allows us to systematize and generalize the available information, and also makes it possible to predict further botanical finds.
\end{abstract}

Key words: cemeterial territories, flora, Kirovsky district, Sovetsky district, Volgograd, the village of Arzgir, Stavropol Territory, botanical herbarium.

Citation. Samokish V.S., Sagalaev V.A. Flora of the Cemeterial Territories of Volgograd and the Village of Arzgir of Stavropol Territory. Prirodnye sistemy i resursy [Natural Systems and Resources], 2021, vol. 11, no. 3, pp. 22-25. DOI: https://doi.org/10.15688/nsr.jvolsu.2021.3.3

УДК 581.91

ББК 28.5

ФЛОРА ЦЕМЕТЕРИАЛЬНЫХ ТЕРРИТОРИЙ Г. ВОЛГОГРАДА И с. АРЗГИР СТАВРОПОЛЬСКОГО КРАЯ

\section{Виктория Сергеевна Самокиш}

Волгоградский государственный университет, г. Волгоград, Российская Федерация

\section{Вадим Александрович Сагалаев}

Волгоградский государственный университет, г. Волгоград, Российская Федерация

Аннотация. В статье впервые приводятся сведения об особенностях растительного сообщества цеметериальных территорий г. Волгограда и с. Арзгир Ставропольского края. Инвентаризация растений проводилась маршрутным методом. Каждый маршрут составлял около 10 километров. Впервые были исследованы 
такие цеметериальные территории, как кладбище поселка Горная Поляна и Кировское кладбище в г. Волгограде, кладбища № 1 и № 2 в с. Арзгир Ставропольского края. Идентификация образцов осуществлялась стандартными методами в лаборатории экспериментальной биологии Волгоградского государственного университета (ВолГУ). Собранные виды хранятся в Ботаническом гербарии университета. В статье представлен аннотированный список растений цеметериев, включающий 44 вида, с указанием данных о местообитаниях и дате сбора. Данный аннотированный список будет основой для проведения мониторинговых исследований в области охраны окружающей среды, а также оптимизации региональной сети ООПТ. Проведен сравнительный анализ флор исследуемых территорий, согласно которому было выявлено незначительное различие. Оно объясняется тем, что цеметериальные территории г. Волгограда находятся внутри крупнейшего урбанизированного города, в отличие от небольшого с. Арзгир, а также видовой состав растений двух данных территорий зависит от человека, так как большинство видов являются культивируемыми. Полученные в результате исследования данные будут использованы для разработки вопросов систематики, географии и экологии растений. Выявленное разнообразие растений исследуемых регионов расширяет наше знание об экологии и распространении видов, позволяет систематизировать и обобщить имеющуюся информацию, а также дает возможность прогнозировать дальнейшие ботанические находки.

Ключевые слова: цеметериальные территории, флора, Кировский район, Советский район, г. Волгоград, с. Арзгир, Ставропольский край, ботанический гербарий.

Цитирование. Самокиш В. С., Сагалаев В. А. Флора цеметериальных территорий г. Волгограда и с. Арзгир Ставропольского края // Природные системы и ресурсы. - 2021. - Т. 11, № 3. - С. 22-25. - DOI: https://doi.org/10.15688/nsr.jvolsu.2021.3.3

\section{Введение}

Анализ видового разнообразия является основой для понимания процессов формирования и функционирования биоценозов, при этом растения, как важный компонент биоценоза, часто слабо изучены, хотя их всестороннее исследование имеет важное теоретическое и практическое значение. Флора исследуемых цеметериальных территорий никем еще не была исследована до настоящего времени.

Кладбище является неотъемлемой частью городской и сельской экосистемы. Формирование состава флоры данных территорий напрямую зависит от времени возникновения кладбища, наличия исходных микоцинозов, их экологических особенностей и т. П. Кроме того, цеметериальные территории являются источниками видов-интродуктов и здесь нередко сохраняются участки, не подверженные значительной антропогенной трансформации. Исходя из этого следует, что для выявления прежнего состояния растений необходимо проводить флористические исследования по инвентаризации растений цеметериальных территорий.

\section{Материалы и методы исследования}

Исследование флоры цеметериальных территорий проводилось маршрутным мето- дом в период с июля по ноябрь 2020 года. Сбор и обработка материала ${ }^{1}$ осуществлялись по методике А.К. Скворцова (1977) [5]. Был также проведен микроскопический анализ образцов. Идентификация собранного материала проводилась в лаборатории кафедры биологии ВолГУ на основе методов световой микроскопии (Микроскоп БМС-1 и Микмед-5 с камерой - Levenhuk C510 NG) [1-6].

\section{Результаты и их обсуждения}

Ниже представлен аннотированный список растений, найденных в настоящее время на территории цеметериев г. Волгограда и с. Арзгир Ставропольского края.

Названия видов расположены по местообитанию. В аннотациях к видам указаны данные о местообитаниях и дате сбора.

22 июля 2020 г. в с. Арзгир на кладбище № 2 обнаружены следующие виды: Ailanthus altissima (Mill.) Swingle, Asparagus officinalis L., Atriplex micrantha C. A. Mey., Betula pendula Roth, Centaurea diffusa Lam., Cuscuta campestris Yunck, Delphinium consolida L., Euphorbia humifusa Willd., Euphorbia segnieriana Neck, Falaria vulgaris Bernh, Goniolimon tataricum (L.) Boiss., Inula Britannica L., Platycladus orientalis (L.) Franco, Salix alba L., Salvia stepposa Des.- 
Shost., Sedobassia sedoides (Pall.) Freitag \& G. Kadereit, Sempervivum caucasicum Rupr. ex Boiss., Setaria viridis (L.) P. Beauv., Solonum cornutum Lam., Stypholobium japanicum (L.) Schott, Syringa vulgaris L.

12 августа 2020 г. в с. Арзгир на кладбище № 1 найдены такие виды, как: Agropyron desertorum (Fisch. Ex Link) Schulf, Atriplex micrantha C. A. Mey., Atriplex tatarica L., Betula pendula Roth, Elytrigia repens (L.) Nevski, Glyrrhiza aspera Pall., Goniolimon tataricum (L.) Boiss., Helichrysum nogaicum Tzvelev, Hylotelephium triphyllum (Haw.) Holub, Sedum acre L., Sempervivum caucasicum Rupr. ex Boiss., Syringa vulgaris L.

2 ноября 2020 г. в Советском районе г. Волгограда на кладбище поселка Горная Поляна были обнаружены данные виды: Agropyron desertorum (Fisch. Ex Link) Schulf, Artemisia marschalliana Spreng., Calamagrostis epigeios (L.) Roth, Carduus uncinatua M. Bieb., Cenchrus panciflorus Benth, Centaurea diffusa Lam., Conyza canadensis (L.) Cronquist, Cuscuta campestris Yunck, Glyrrhiza aspera Pall., Helichrysum arenarium (L.) Moench, Pinus sylvestris L., Platycladus orientalis (L.) Franco, Salsola tragus L., Salvia stepposa Des.-Shost., Sorbus hybrid (L.) L.

4 ноября 2020 г. в Кировском районе г. Волгограда на Кировском кладбище выявлены такие виды, как: Achillea micrantha Willd., Artemisia lercheana Weber ex Stechm, Asparagus officinalis L., Atriplex tatarica L., Centaurea adpessa Ledeb., Cleistogenes bulgarica (Bornm.) Keng, Delphinium consolida L., Gypsophila paniculata L., Hylotelephium triphyllum (Haw.) Holub, Polygonum aviculare L., Sisymbrium altissimum L., Syringa vulgaris L.

\section{Заключение}

Таким образом, в результате таксономического анализа флоры цеметериальных территорий Советского и Кировского районов г. Волгограда Волгоградской области и с. Арзгир Ставропольского края было выявлено 2 отдела, 4 класса, 22 порядка 23 семейства, 44 вида растений.

\section{ПРИМЕЧАНИЕ}

${ }^{1}$ Авторы выражают глубокую признательность за помощь при сборе и определении материала Н.С. Курагиной, В.В. Землянко, А.А. Копаковой.

\section{СПИСОК ЛИТЕРАТУРЫ}

1. Галушко, И. А. Флора Северного Кавказа : определитель / А. И. Галушко. - Ростов н/Д : Изд-во Рост. ун-та, 1980. - 351 с.

2. Иллюстрированный определитель растений Средней России : в 3 т. / И. А. Губанов [и др.]. М. : Т-во науч. изд. КМК, 2002-2004. - Т. 1 : Папоротники, хвощи, плауны, голосеменные, покрытосеменные (однодольные). - 2002. - 526 с. ; Т. 2 : Покрытосемянные (двудольные: раздельнолепестные). - 2003. - 668 с. ; Т. 3 : Покрытосемянные (двудольные: раздельнолепестные). - 2004. - 521 с.

3. Новиков, В. С. Популярный атлас определитель. Дикорастущие растения / В. С. Новиков, И. А. Губанов. - М. : Дрофа, 2007. -415 с.

4. Решетникова, Н. М. Флора Нижнего Поволжья. В 2 т. Т. 2. Раздельнолепестные двудольные сосудистые растения / Н. М. Решетникова. - М. : Т-во науч. изд. КМК, 2018. - 519 с.

5. Скворцов, А. К. Гербарий : пособие по методике и технике / А. К. Скворцов. - М. : Наука, 1977. -199 c.

6. Скворцов, А. К. Флора Нижнего Поволжья. В 2 т. Т. 1 / А. К. Скворцов. - М. : Т-во научных изданий КМК, 2006. -435 с.

\section{REFERENCES}

1. Galushko I.A. Flora Severnogo Kavkaza: opredelitel [Flora of the North Caucasus. Determinant]. Rostov-on-Don, Izd-vo Rostovskogo universiteta, 1980.351 p.

2. Gubanov I.A., Kiseleva K.V., Novikov V.S., Tikhomirov V.N. Illyustrirovannyy opredelitel rasteniy Sredney Rossii: $v 3 t$. [Illustrated Determinant of Plants of Central Russia. In 3 Vols.]. Moscow, Tovarishchestvo nauchnykh izdaniy KMK, 2002-2004, vol. 1: Paporotniki, khvoshchi, plauny, golosemennye, pokrytosemennye (odnodolnye) [Ferns, Horsetails, Plauns, Gymnosperms, Angiosperms (Monocotyledons)], 2002. 526 p.; vol. 2: Pokrytosemiannye (dvudolnye: razdelnolepestnye) [Angiosperms (Dicotyledons: Split-Bladed)], 2003. 668 p.; vol. 3: Pokrytosemiannye (dvudolnye: razdelnolepestnye) [Angiosperms (Dicotyledons: SplitBladed)], 2004. 521 p.

3. Novikov V.S., Gubanov I.A. Populiarnyi atlas opredelitel. Dikorastushchie rasteniia [Popular 
Atlas Determinant. Wild Plants]. Moscow, Drofa Publ., 2007. 415 p.

4. Reshetnikova N.M. Flora Nizhnego Povolzhia. V 2 t. T. 2. Razdelnolepestnye dvudolnye sosudistye rasteniia [Flora of the Lower Volga Region. In 2 Vols. Vol. 2. Dialypetalous Dicotyledonous Vascular Plants]. Moscow, Tovarishchestvo nauchnykh izdaniy KMK, 2018. 519p.
5. Skvortsov A.K. Gerbariy: posobie po metodike i tekhnike [Herbarium. Manual on Methodology and Technology]. Moscow, Nauka Publ., 1977. 199 p.

6. Skvortsov A.K. Flora Nizhnego Povolzhia. V 2 t. T. 1 [Flora of the Lower Volga Region. In 2 Vols. Vol. 1]. Moscow, Tovarishchestvo nauchnykh izdaniy KMK, 2006. 435 p.

\section{Information About the Authors}

Victoria S. Samokish, Student, Department of Biology, Volgograd State University, Prosp. Universitetsky, 100, 400062 Volgograd, Russian Federation, viktorya.samokish@yandex.ru

Vadim A. Sagalaev, Doctor of Sciences (Biology), Associate Professor, Professor, Department of Biology, Volgograd State University, Prosp. Universitetsky, 100, 400062 Volgograd, Russian Federation, alex_sag@mail.ru

\section{Информация об авторах}

Виктория Сергеевна Самокиш, студент кафедры биологии, Волгоградский государственный университет, просп. Университетский, 100, 400062 г. Волгоград, Российская Федерация, viktorya.samokish@yandex.ru

Вадим Александрович Сагалаев, доктор биологических наук, доцент, профессор кафедры биологии, Волгоградский государственный университет, просп. Университетский, 100, 400062 г. Волгоград, Российская Федерация, alex_sag@mail.ru 